\title{
Fabrication and Antibacterial Effects of Polycarbonate/Leaf Extract Based Thin Films
}

\author{
R. Mahendran, ${ }^{1}$ D. Sridharan, ${ }^{1}$ C. Arunmozhidevan, ${ }^{1}$ T. A. Selvakumar, ${ }^{2}$ and P. Rajasekar ${ }^{2}$ \\ ${ }^{1}$ Department of Chemistry, Anjalai Ammal Mahalingam Engineering College, Anna University, Kovilvenni 614 403, India \\ ${ }^{2}$ Department of Biotechnology, Rajalakshmi Engineering College, Anna University, Thandalam, Chennai 602105, India
}

Correspondence should be addressed to R. Mahendran; anishmahendran10@gmail.com

Received 22 April 2016; Revised 23 August 2016; Accepted 1 September 2016

Academic Editor: Huan-Tsung Chang

Copyright (C) 2016 R. Mahendran et al. This is an open access article distributed under the Creative Commons Attribution License, which permits unrestricted use, distribution, and reproduction in any medium, provided the original work is properly cited.

We have reported the preparation and antibacterial activities of leaf extract incorporated polycarbonate thin films to improve the antibacterial characteristics of host polycarbonates (PCs). Crude extracts of Azadirachta indica, Psidium guajava, Acalypha indica, Andrographis paniculata, and Ocimum sanctum were prepared by maceration using Dimethylformamide as solvent. The leaf extracts (LE) were incorporated into the PC matrix by solution blending method, and the thin films were fabricated by Thermally Induced Phase Separation (TIPS) technique. The antibacterial activities of the as-prepared films were evaluated against E. coli and S. aureus by disk diffusion method. The inhibitory effects of the PC/LE films are higher for S. aureus than the E. coli, but pristine PC film did not exhibit any remarkable antibacterial characteristics. Further, the model fruit (Prunus) studies revealed that the PC/LE films retained the freshness of the fruits for more than 11 days. This study demonstrates that the PC/LE films have excellent antibacterial activities; thus, the films could be promising candidate for active antibacterial packaging applications.

\section{Introduction}

Bacterial growth on food surface is the main cause of spoilage of the foods. In order to control undesirable bacterial activities on foods, antibacterial packaging films are being utilized to keep the food safe. The antibacterial materials inhibit/reduce the ability of bacterial colonies to grow on the surface of the food. Generally, the antibacterial materials are blended/immobilized/coated on the packaging materials to prolong shelf-life, sensory properties, and freshness of the food [1]. Furthermore, antibacterial materials protect the food from pathogens, oxygen, moisture, and dust. Generally, antibacterial materials have been fabricated by incorporating biologically active compounds such as antioxidants and flavoring agents into matrix/coating of the packaging material $[2,3]$, which reduce the growth of bacteria.

Conventionally, the metal nanoparticles are being impregnated into the polymer matrix for enhancing their antibacterial activities; however, they have certain drawbacks such as high cost, toxicity, harmfulness, and problems in disposal of the wastes $[4,5]$. In order to overcome these difficulties, ecofriendly antibacterial materials such as medicinal leaf extract are used for destroying Gram-positive and Gram-negative bacteria [6]. The leaf extracts are in liquid form, which protect their commercial applications in active packaging materials. This major drawback could be overcome by incorporating the leaf extract into the polymer matrix for the fabrication of films, which can protect the food and beverages from the bacterial attack. Generally, most of the leaf extracts have rich content of tannins, terpenoids, alkaloids, flavonoids, glycosides, and polyphenols, which was clearly identified as their in vitro antibacterial activities.

The biodegradable polymers like cellulosic polymers have been utilized for the fabrication of antibacterial packaging films; however, their water sensitivity, poor interfacial adhesion, and low melting point reduce their potential applications. In order to overcome these drawbacks, polycarbonate (PC) based thin films have been used for food packaging, due to their hydrophobic nature, durability, dimensional stability, light weight, excellent mechanical and thermal stabilities, and moisture barrier properties, which are the essential characteristics for active antibacterial packaging films. The 
PCs have been studied in a number of applications by direct contact with foods and beverages; however, they have very poor antibacterial activities, which reduce their efficiency in antibacterial packaging system effectively. The antibacterial activities of the PC have been enhanced by functionalizing reactive groups/blending with antibacterial agents [7-9].

In this research, we have reported leaf extract incorporated PC films, which were fabricated using solution blending followed by Thermally Induced Phase Separation technique. Here, the maceration was employed for preparing the leaf extract, in which the solvents diffuse into the solid plant material and solubilize their compounds. The as-prepared leaf extracts are safe and effective for long term use, since they possess antibacterial molecules as well as antioxidants. The following medicinal leaves crude extracts were used in this study. Firstly, the extract that was collected from the leaf of Azadirachta indica (neem) has flavonoids, dihydrochalcones, arabinogalactans, isoprenoids, polyphenolics, coumarin, and tannins, which are the important constituents for its antibacterial activities [10]. Then, Psidium guajava (Guava) leaf extract consists of effective phytochemical constituents such as acalypus, tannins, saponins, and acalyphine for its antibacterial nature [11]. Acalypha indica, commonly known as Indian Acalypha, has potential antibacterial molecules such as acalyphine, cyanogenic glucosides, alkaloids, and triacetone amine. Furthermore, the leaf extract of Andrographis paniculata (Green Chiretta) contains flavonoids, alkaloids, steroids, phenols, tannins, and particularly andrographolide for its antibacterial efficacy [12]. Finally, the fresh leaf of Ocimum sanctum (Holy Basil) possesses steroid, flavonoid, phenols, tannin, alkaloid, saponin, and carotenoid compounds, and it could be also used as insecticide, antibiotics, and fungicide [13]. All the leaf extracts possess the vital properties like antifungal, antiviral, antioxidant, anti-inflammatory, and antipyretic. Based on the above merits, the mentioned leaf extract was prepared by maceration for blending with the PC solution to obtain active antibacterial thin films.

Here, we report a facile, low-cost, and scalable technique for the fabrication of PC/LE films. In addition, the antibacterial activities of the PC and PC/LE films were assessed against $S$. aureus and $E$. coli, which are identified as food spoilage bacteria. To the best of our knowledge, in an open literature, the antibacterial studies of mentioned crude leaf extract incorporated PC thin films have not yet been reported for active antibacterial packaging applications.

\section{Materials and Methods}

2.1. Materials. Bisphenol A polycarbonate $\left(\mathrm{PC} ; M_{w} \sim\right.$ $1,50,000 \mathrm{~g} / \mathrm{mol}$ molecular weight of repeating unit: $254.3 \mathrm{~g} /$ mol; polydispersity index: 1.8) was supplied by GE Plastic, Ltd., India, and dried at $100^{\circ} \mathrm{C}$ in an oven for $6 \mathrm{hrs}$ prior to use. Azadirachta indica, Psidium guajava, Acalypha indica, Andrographis paniculata, and Ocimum sanctum were collected at various regions, which were mentioned in Table 1. Prunus (plum), fruit model, were cleaned with distilled water several times to remove the adhering impurities on the surface. N,N-Dimethylformamide (DMF) was purchased from Sigma-Aldrich, India, and used as received. The list of abbreviations of the chemicals and leaves used in this study is listed in Abbreviations.

2.2. Processing of the Leaf. Firstly, the leaves (Azadirachta indica, Psidium guajava, Acalypha indica, Andrographis paniculata, and Ocimum sanctum) were washed with running tap water for $15 \mathrm{~min}$, followed by distilled water several times to remove the impurities on the leaves' surface. The samples were dried at room temperature under shade for 10 days to evaporate the residual water. The leaves were finely ground by stainless steel grinder to turn them to powdery form and stored in airtight containers $[14,15]$.

2.3. Preparation of Leaf Extract. Powdered leaf (10 g) was poured in an Erlenmeyer flask containing $100 \mathrm{~mL}$ of DMF. The flask was put on a hot plate for $10 \mathrm{~min}$ and kept aside for $24 \mathrm{~h}$ at room temperature for complete maceration. Then, the macerate was filtered through nylon mesh followed by Whatman number 1 filter paper. The similar procedure was followed by preparing all the leaf crude extracts. In addition, for the preparation of PC-AI 2 and PC-AI 3 samples, $20 \mathrm{~g}$ and $30 \mathrm{~g}$ of dried neem powder were macerated in DMF $(100 \mathrm{~mL})$, respectively [16].

2.4. Fabrication of PC and PC/LE Films. The PC and PC/LE thin films were fabricated by solution blending followed by TIPS [17, 18]. Figure 1 shows the schematic representation of the fabrication of PC/LE thin films. The figure reveals the processing of neem leaves, maceration of the neem powder, and the appearance of as-prepared film with inhibition zones, respectively. Briefly, the PC (15 wt\%) was dissolved in DMF and stirred for 5 hrs by magnetic stirring to obtain a homogeneous solution. Consequently, the as-prepared leaf extract $(10 \mathrm{~mL})$ was added to the PC solution, with stirring for $5 \mathrm{hrs}$ at room temperature. The PC/LE solution was poured on a glass plate and cast by a doctor blade (thickness $50 \mu \mathrm{m})$ at room temperature. The nascent film was being kept on a hot plate $\left(80^{\circ} \mathrm{C}\right)$ to evaporate the solvent. Then, the film was peeled off and placed in a stainless steel plate at $100^{\circ} \mathrm{C}$ for $2 \mathrm{hr}$ to remove the residual solvent completely. The thickness of the as-prepared films was measured using a digital micrometer (Mitutoyo, Tokyo, Japan), at different locations and an average value of six measurements was taken for each film.

2.5. Fruit Model Studies. The antibacterial efficacy of the PC and PC/LE films was assessed using genus Prunus as a model fruit. Fresh Prunus of almost equal size were washed with distilled water and then dried at room temperature for $3 \mathrm{hrs}$. Prunus was wrapped with the as-prepared films individually and placed in an open atmosphere, and the unwrapped Prunus was served as control [19].

2.6. Evaluation of Antibacterial Activity. The antibacterial activities of the PC and PC/LE films were assessed using E. coli (Gram-negative, ATCC 25922) and S. aureus (Grampositive, ATCC29213) by Disc Diffusion method (Kirby 
TABLE 1: Descriptive features of the leaf used for the antibacterial assay.

\begin{tabular}{lcccc}
\hline S. number & Botanical species & Family name & Location & Studied organ \\
\hline 1 & Acalypha indica & Myrtaceae & $\mathrm{N} 10^{\circ} 47^{\prime} 13^{\prime \prime}$ & Leaves \\
2 & Psidium guajava & Euphorbiaceae & $\mathrm{N} 10^{\circ} 46^{\prime} 19^{\prime \prime}$ & Leaves \\
3 & Andrographis paniculata & Acanthaceae & $\mathrm{N} 10^{\circ} 39^{\prime} 36^{\prime \prime}$ & Leaves \\
4 & Ocimum sanctum & Lamiaceae & $\mathrm{N} 10^{\circ} 46^{\prime} 19^{\prime \prime}$ & Leaves \\
5 & Azadirachta indica & Meliaceae & $\mathrm{N} 10^{\circ} 39^{\prime} 36^{\prime \prime}$ & Leaves \\
\hline
\end{tabular}
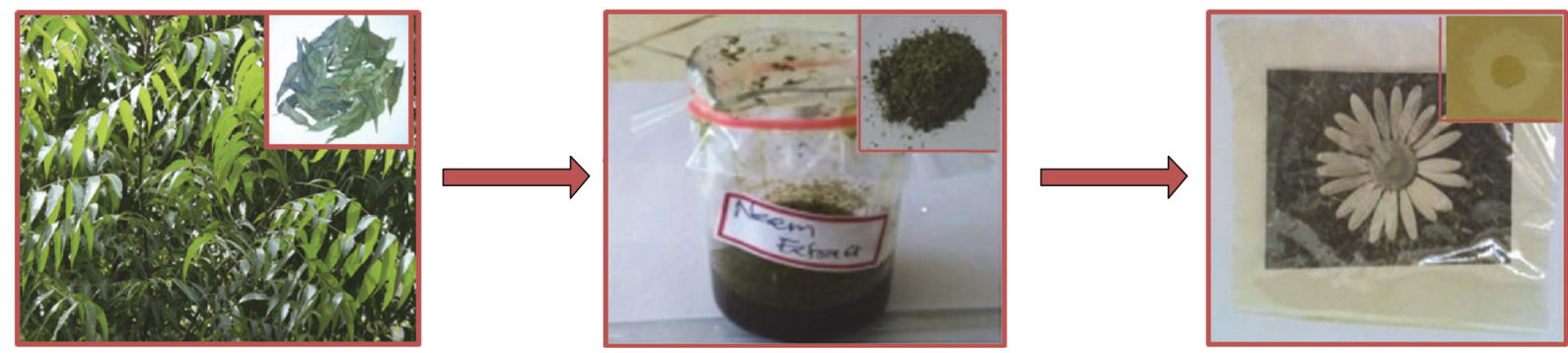

FIGURE 1: Schematic representation of fabrication of PC/LE thin films.

Bauer test) [20, 21]. Briefly, the sterilized Mueller-Hinton agar was poured in Petri plates; after solidification, the inoculums were spread on the plate using L-rod. Later, the as-prepared films were cut into pieces and placed on the bacterial strain. The plates were incubated for $24 \mathrm{~h}$ in an aerobic incubation chamber. The inhibition zones around the films were visually identified and the diameter of the inhibition zone was also measured.

\section{Results and Discussion}

Table 2 shows the PC/LE weight ratio and thickness of the as-prepared thin films. The thickness of the PC-AI 1, PC-AI 2 , and PC-AI 3 thin films minutely increased with respect to the concentration of neem leaf extract in the PC matrix, and the thickness of the remaining films did not change significantly. Figure 2 shows the PC, PC-AC, PC-PG, PCOS, PC-AI 1, PC-AI 2, and PC-AI 3 transparent thin films on the flower image; the color of the films shifted from dull to dark greenish with respect to the chlorophyll and other constituents in content of the leaf extract [22]. The pristine PC film appears transparent and colorless, which is shown in Figure 2. However, the PC-AC, PC-PG, and PC-OS films have light greenish color, due to low content of chlorophyll in their leaf. Since the content of neem leaf extract increased from 10 to $30 \mathrm{wt} \%$, the color of the resulting films changed from light green (PC-AI 1) to dark green (PC-AI 3). At higher quantity $(40 \mathrm{~mL})$ of Azadirachta indica leaf extract in the polymer matrix, the film lost its transparency slightly, and the leaf extract did not homogeneously mix within the matrix.

Figure 3 shows photographic images of the model fruit sample of Prunus, unwrapped control and wrapped with pristine PC and PC/LE films. The preservation study had been carried out for 11 days, until the control and PC wrapped
TABLE 2: Composition and thickness of as-prepared PC and PC/LE thin films.

\begin{tabular}{lcccc}
\hline S. number & $\begin{array}{c}\text { Thin film } \\
\text { code }\end{array}$ & $\begin{array}{c}\text { PC } \\
(\mathrm{wt} \%)\end{array}$ & $\begin{array}{c}\text { Leaves extract } \\
(\mathrm{mL})\end{array}$ & $\begin{array}{c}\text { Thickness } \\
(\mu \mathrm{m})\end{array}$ \\
\hline 1 & PC & 30 & 10 & 17 \\
2 & PC-AC & 30 & 10 & 25 \\
3 & PC-PG & 30 & 10 & 24 \\
4 & PC-AP & 30 & 10 & 23 \\
5 & PC-OS & 30 & 10 & 26 \\
6 & PC-AI 1 & 30 & 10 & 27 \\
7 & PC-AI 2 & 30 & 20 & 29 \\
8 & PC-AI 3 & 30 & 30 & 30 \\
\hline
\end{tabular}

Prunus spoiled. After 11 days, Prunus wrapped with the PC/LE films retained higher shelf-life and freshness, compared with the control and PC wrapped one. In these fruit model studies, the control sample started to deteriorate after 3 days, and the PC wrapped sample deteriorated after 5 days. From the images (Figure 3), it can be concluded that Prunus (control) and Prunus covered with pristine PC film started to damage and deteriorate due to the attack of bacterial pathogens, whereas Prunus wrapped with the PC/LE films maintained freshness and the shape of the fruit, even after 11 days of storage time due to their antibacterial characteristics [23].

Figure 4 shows photographic images of PC and PC/LE films on the bacterial lawn. The pristine PC films did not show any significant inhibition zone for both bacteria, whereas the PC/LE films were more effective and exhibited inhibition zones for E. coli and S. aureus. This is due to the presence of antibacterial agents in the leaf extracts, which did effectively function in the PC matrix. In this research, all the PC/LE films possessed significant inhibitory activities against $E$. coli and $S$. 

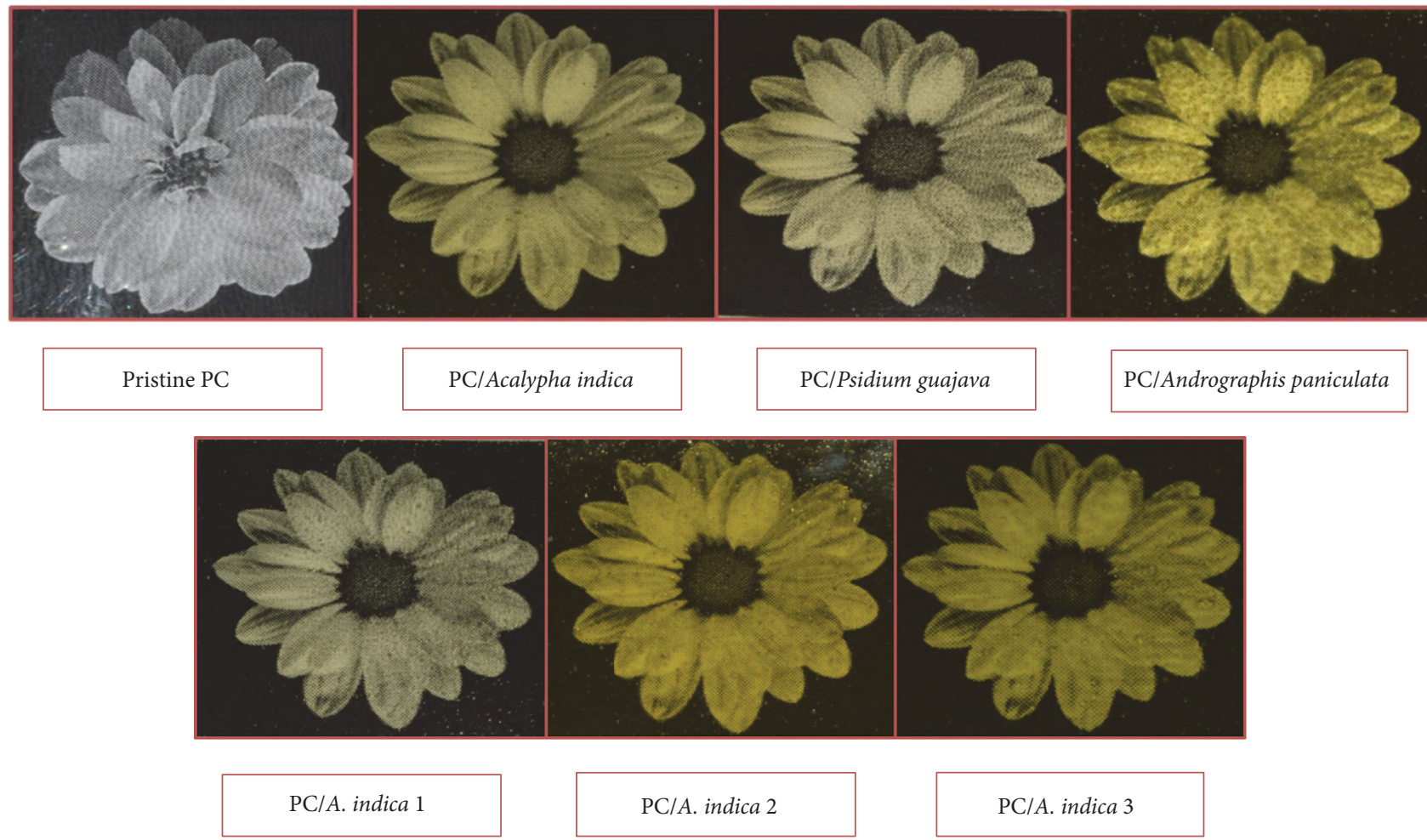

FIgure 2: Photographic images of PC and PC/LE thin films.

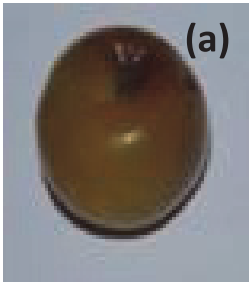

(a)

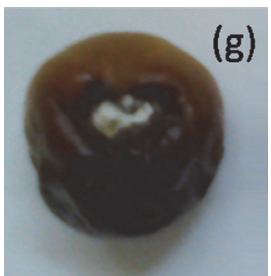

(g)

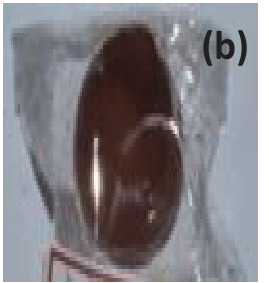

(b)

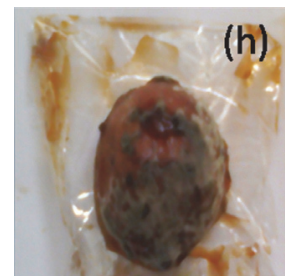

(h)

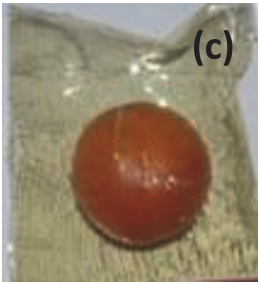

(c)

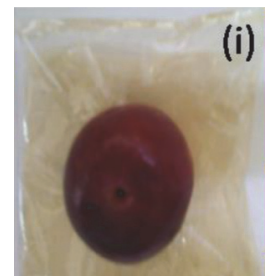

(i)

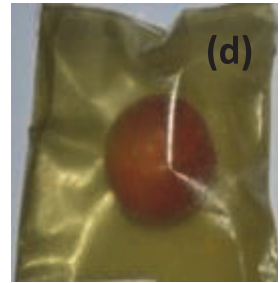

(d)

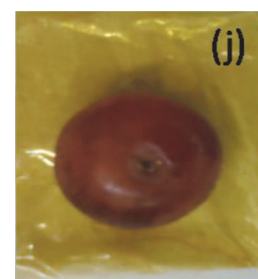

(j)

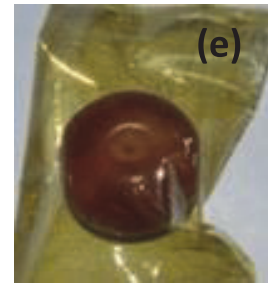

(e)

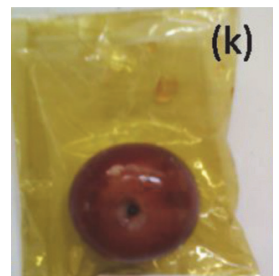

(k)

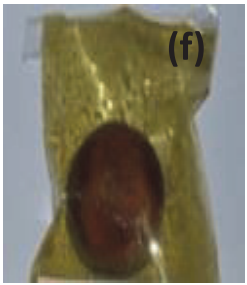

(f)

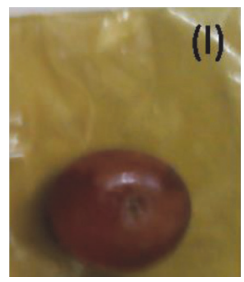

(1)

Figure 3: Photographic images of Prunus (a), pristine PC (b), PC-AC (c), PC-PG (d), PC-OS (e), and PC-AI 1 (f). After 11 days, Prunus (g), pristine PC (h), PC-AC (i), PC-PG (j), PC-OS (k), and PC-AI 1 (l).

aureus, which concluded that the leaf extracts also retain their antibacterial property in the polymer matrix.

In Figure 5, the PC-OS sample showed the highest inhibition zones of 8.21 and $7.82 \mathrm{~mm}$ for E. coli and S. aureus, respectively, due to the presence of effective antibacterial agents such as saponins, alkaloids, flavonoids, cardiac glycosides, steroids, phenols, and tannin [24]. In the PC-AI 1-3 films, since the leaf extract concentration was increased from $10 \mathrm{~mL}$ to $30 \mathrm{~mL}$, the antibacterial activity of the films also was significantly enhanced, meaning that the bacteria have been killed faster at higher concentration of antibacterial agents in the PC films [25]. The antibacterial studies revealed that the efficacy of the antibacterial agents against $S$. aureus was higher for all the films compared with E. coli. This might be 


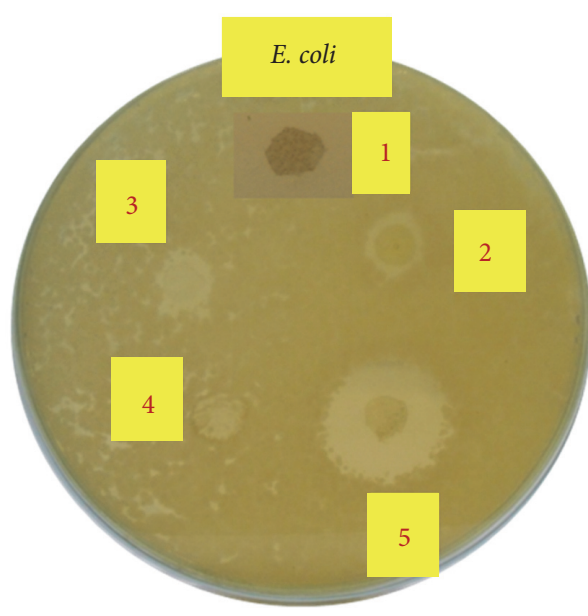

(a)

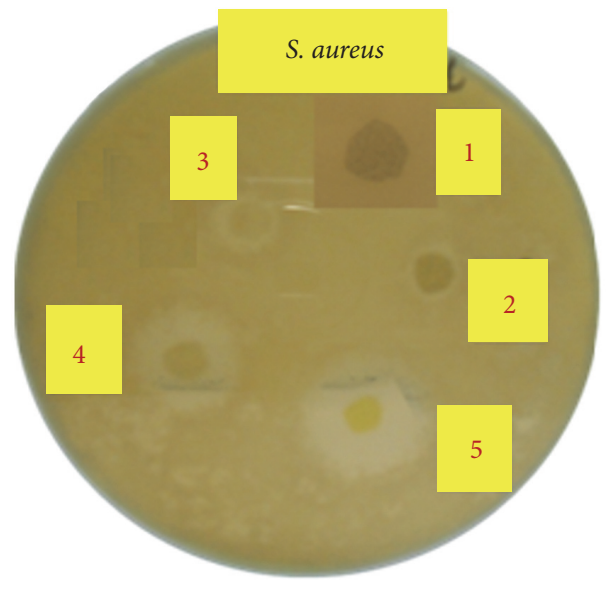

(c)

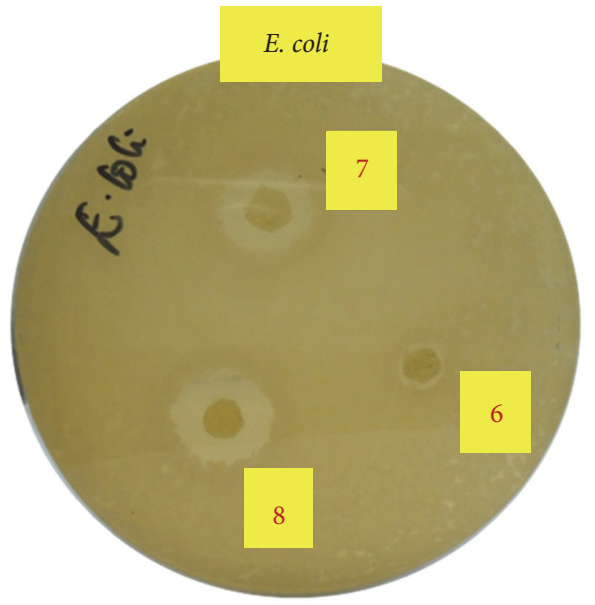

(b)

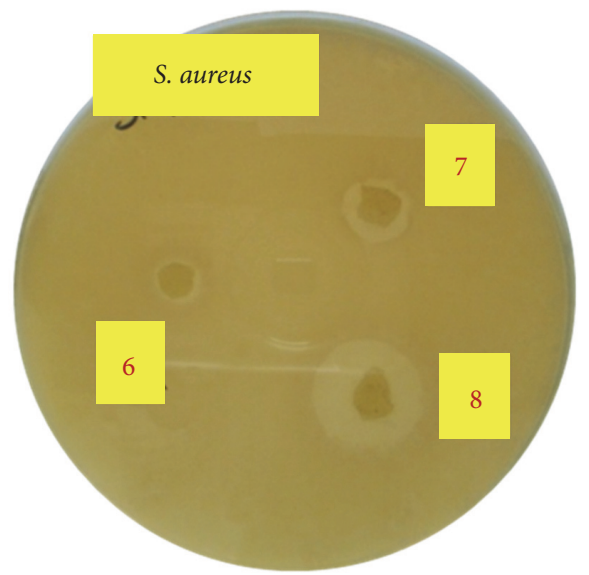

(d)

FIgURE 4: Inhibition zones of films against E. coli (a and b) and S. aureus (c and d): PC (1), PC-AC (2), PC-PG (3), PC-AP (4), PC-OS (5), PC-AI 1 (6), PC-AI 2 (7), and PC-AI 3 (8).

due to the fact that the damage of cell wall structure of the $S$. aureus is easier than the E. coli by bactericidal molecules in the leaf extract. For E. coli, the PC-AC, PC-PG, PC-AP, PCOS, PC-AI 1, and PC-AI 2 exhibited the inhibition zones of $3.24,2.13,3.32,8.12,1.32$, and $4.51 \mathrm{~mm}$, respectively. In case of $S$. aureus, the inhibition zones were observed around 3.43, $3.30,5.43,7.64,1.16,4.21$, and $6.48 \mathrm{~mm}$ for the PC-AC, PCPG, PC-AP, PC-OS, PC-AI 1, and PC-AI 2, respectively. The results concluded that the antibacterial agents present in the leaf effectively destroyed the $S$. aureus more than the E. coli.

\section{Conclusion}

A simple and reliable route has been proposed to fabricate bactericidal films by incorporating leaf extract into the polymer matrix. The as-prepared films showed significant antibacterial activities against $E$. coli and S. aureus. Specifically, P. guajava based PC thin films exhibited the highest antibacterial activities against both bacteria even at low loading $(10 \mathrm{wt} \%)$ of leaf extract in the polymer matrix. Most of the films showed excellent inhibitory effects against $S$. aureus compared to the E. coli. More importantly, the model fruit studies revealed that the as-prepared PC/LE films could be the promising materials in antibacterial packaging applications due to their significant antibacterial efficacy.
Abbreviations
PC: $\quad$ Polycarbonate
LE: $\quad$ Leaf extract
S. aureus: Staphylococcus aureus
E. coli: Escherichia coli
DMF: N,N-Dimethylformamide
AC: Acalypha indica
PG: $\quad$ Psidium guajava
AP: $\quad$ Andrographis paniculata
OS: $\quad$ Ocimum sanctum
AI: Azadirachta indica. 


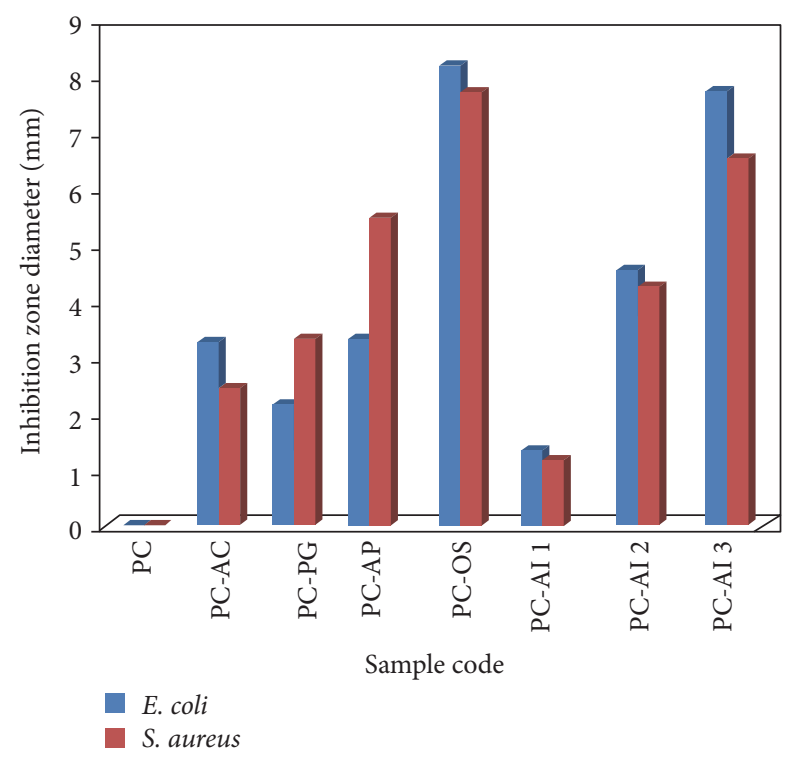

FIgURE 5: Comparison of antibacterial activities of PC and PC/LE films against $E$. coli and $S$. aureus.

\section{Competing Interests}

The authors declare that there are no competing interests regarding the publication of this paper.

\section{References}

[1] R. Shemesh, M. Krepker, D. Goldman et al., "Antibacterial and antifungal LDPE films for active packaging," Polymers for Advanced Technologies, vol. 26, no. 1, pp. 110-116, 2014.

[2] L. H. Chong, M. M. Lim, and N. Sultana, "Fabrication and evaluation of polycaprolactone/gelatin-based electrospun nanofibers with antibacterial properties," Journal of Nanomaterials, vol. 2015, Article ID 970542, 8 pages, 2015.

[3] L. Vermeiren, F. Devlieghere, M. Van Beest, N. De Kruijf, and J. Debevere, "Developments in the active packaging of foods," Trends in Food Science and Technology, vol. 10, no. 3, pp. 77-86, 1999.

[4] G. M. Raghavendra, J. Jung, D. kim, and J. Seo, "Microwave assisted antibacterial chitosan-silver nanocomposite films," International Journal of Biological Macromolecules, vol. 84, pp. 281-288, 2016.

[5] M. A. Awad, W. K. Mekhamer, N. M. Merghani et al., "Green synthesis, characterization, and antibacterial activity of silver/polystyrene nanocomposite," Journal of Nanomaterials, vol. 2015, Article ID 943821, 6 pages, 2015.

[6] S.-A. Riyajan and J. Nuim, "Interaction of green polymer blend of modified sodium alginate and carboxylmethyl cellulose encapsulation of turmeric extract," International Journal of Polymer Science, vol. 2013, Article ID 364253, 10 pages, 2013.

[7] J. Xu, E. Feng, and J. Song, "Renaissance of aliphatic polycarbonates: new techniques and biomedical applications," Journal of Applied Polymer Science, vol. 131, no. 5, Article ID 39822, 2014.

[8] L. Kessler, G. Legeay, A. Coudreuse et al., "Surface treatment of polycarbonate films aimed at biomedical application," Journal of Biomaterials Science, Polymer Edition, vol. 14, no. 10, pp. 11351153, 2003.
[9] S. H. Lee, K. Sung, T.-M. Chung et al., "Preparation of silver nanoparticles and antibiotic test of its polycarbonate films composite," Journal of Nanoscience and Nanotechnology, vol. 8, no. 9, pp. 4734-4737, 2008.

[10] S. Siddiqui, S. Faizi, and B. S. Siddiqui, "Constituents of Azadirachta indica: Isolation and structure elucidation of a new antibacterial tetranortriterpenoid, mahmoodin, and a new protolimonoid, naheedin," Journal of Natural Products, vol. 55, no. 3, pp. 303-310, 1992.

[11] P. Jaiarj, P. Khoohaswan, Y. Wongkrajang et al., "Anticough and antimicrobial activities of Psidium guajava Linn. leaf extract," Journal of Ethnopharmacology, vol. 67, no. 2, pp. 203-212, 1999.

[12] U. S. Mishra, A. Mishra, R. Kumari, P. N. Murthy, and B. S. Naik, "Antibacterial activity of ethanol extract of Andrographis paniculata," Indian Journal of Pharmaceutical Sciences, vol. 71, no. 4, pp. 436-438, 2009.

[13] A. Kumar, R. Shukla, P. Singh, and N. K. Dubey, "Chemical composition, antifungal and antiaflatoxigenic activities of Ocimum sanctum L. essential oil and its safety assessment as plant based antimicrobial," Food and Chemical Toxicology, vol. 48, no. 2, pp. 539-543, 2010.

[14] B. Lapornik, M. Prošek, and A. G. Wondra, "Comparison of extracts prepared from plant by-products using different solvents and extraction time," Journal of Food Engineering, vol. 71, no. 2, pp. 214-222, 2005.

[15] J. Azmir, I. S. M. Zaidul, M. M. Rahman et al., “Techniques for extraction of bioactive compounds from plant materials: a review," Journal of Food Engineering, vol. 117, no. 4, pp. 426-436, 2013.

[16] P. Bergweiler and C. Lütz, "Determination of leaf pigments by HPLC after extraction with N,N-dimethylformamide: ecophysiological applications," Environmental and Experimental Botany, vol. 26, no. 3, pp. 207-210, 1986.

[17] M. Joshi, S. W. Ali, and S. Rajendran, "Antibacterial finishing of polyester/cotton blend fabrics using neem (Azadirachta indica): a natural bioactive agent," Journal of Applied Polymer Science, vol. 106, no. 2, pp. 793-800, 2007.

[18] S. Sodha, K. Wall, S. Redenti, H. Klassen, M. J. Young, and S. L. Tao, "Microfabrication of a three-dimensional polycaprolactone thin-film scaffold for retinal progenitor cell encapsulation," Journal of Biomaterials Science, Polymer Edition, vol. 22, no. 4-6, pp. 443-456, 2011.

[19] D. Shanmugapriya, R. Suriyaprabha, R. Yuvak kumar, and V. Rajendran, "Chitosan-incorporated different nanocomposite HPMC films for antibacterial preservation," Journal of Nanoparticle Research, vol. 16, article 2248, 2014.

[20] I. Bhattacharjee, S. K. Chatterjee, A. Ghosh, and G. Chandra, "Antibacterial activities of some plant extracts used in Indian traditional folk medicine," Asian Pacific Journal of Tropical Biomedicine, vol. 1, no. 2, pp. S165-S169, 2011.

[21] A. Rawani, S. Pal, and G. Chandra, "Evaluation of antimicrobial properties of four plant extracts against human pathogens," Asian Pacific Journal of Tropical Biomedicine, vol. 1, no. 1, pp. S71-S75, 2011.

[22] K. Hayakawa and G. E. Timbers, "Influence of heat treatment on the quality of vegetables: changes in visual green color," Journal of Food Science, vol. 42, no. 3, pp. 778-781, 1977.

[23] P. López, C. Sánchez, R. Batlle, and C. Nerín, "Development of flexible antimicrobial films using essential oils as active agents," Journal of Agricultural and Food Chemistry, vol. 55, no. 21, pp. 8814-8824, 2007. 
[24] S. S. Deo, F. Inam, and R. P. Mahashabde, "Antimicrobial activity and HPLC fingerprinting of crude ocimum extracts," E-Journal of Chemistry, vol. 8, no. 3, pp. 1430-1437, 2011.

[25] K. G. Purushotham, P. Arun, J. J. Jayarani, R. Vasnthakumari, L. Sankar, and B. R. Reddy, "Synergistic in vitro antibacterial activity of Tectonagrandis leaves with tetracycline," International Journal of PharmTech Research, vol. 2, no. 1, pp. 519-523, 2010. 

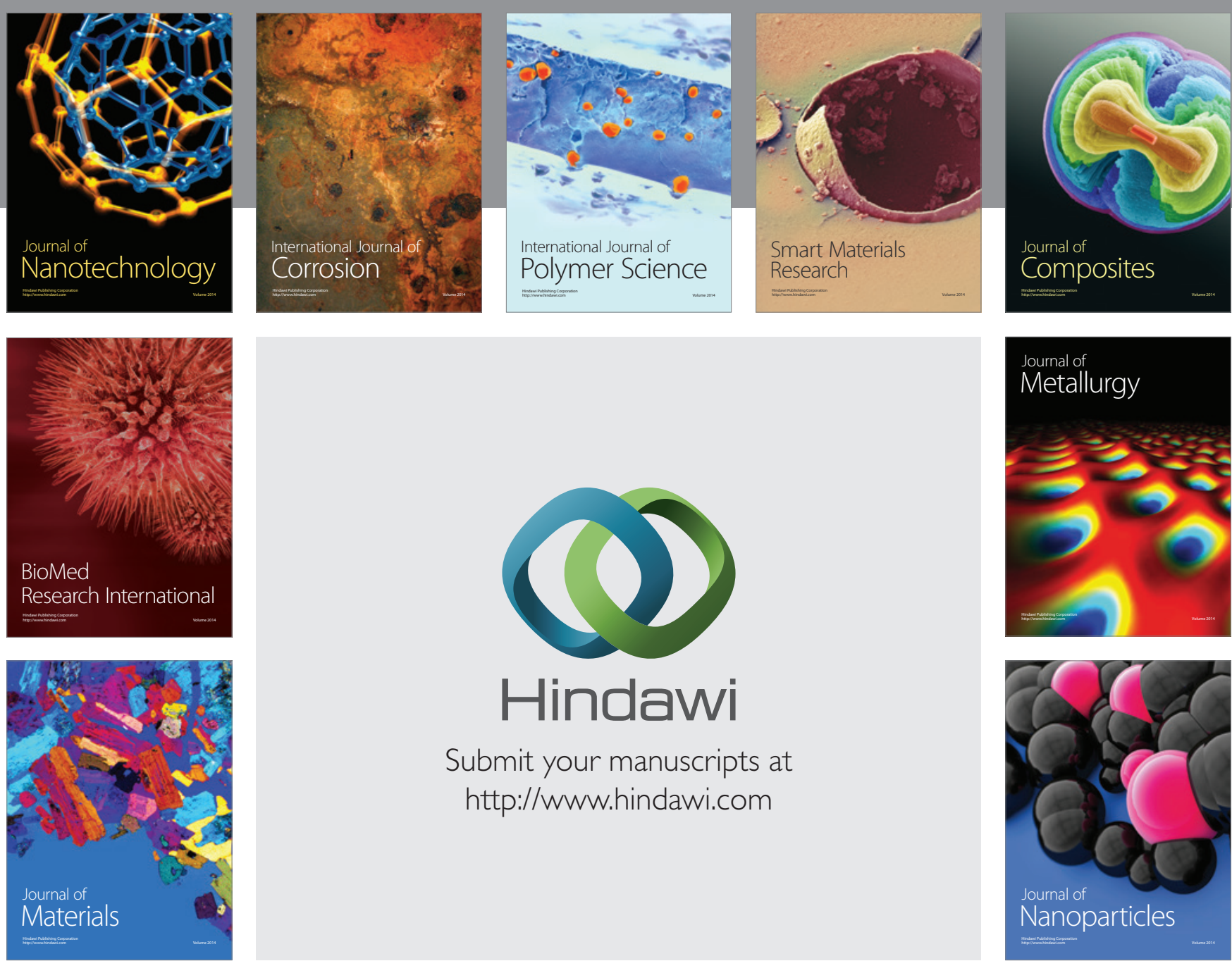

\section{Hindawi}

Submit your manuscripts at

http://www.hindawi.com

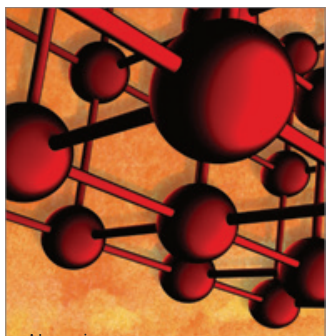

Materials Science and Engineering
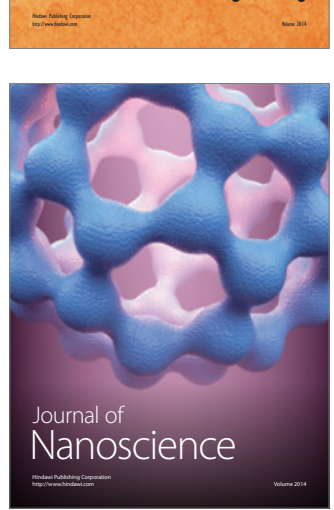
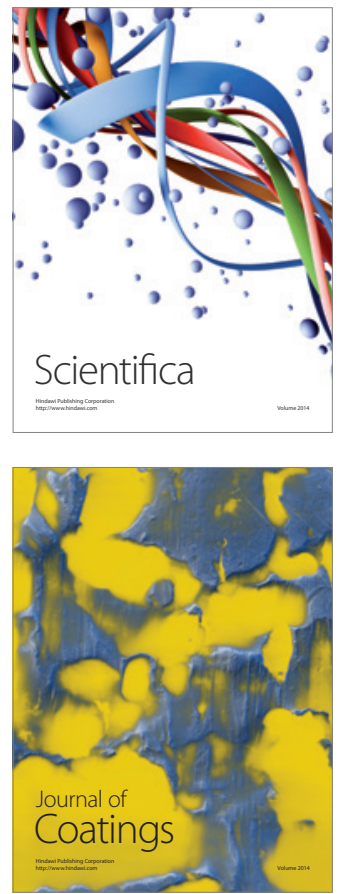
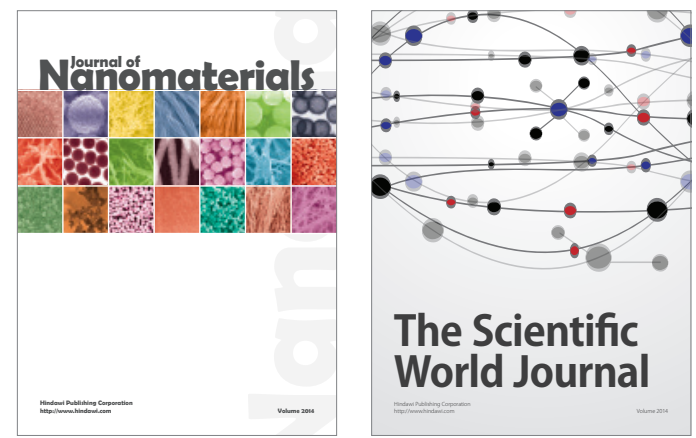

The Scientific World Journal
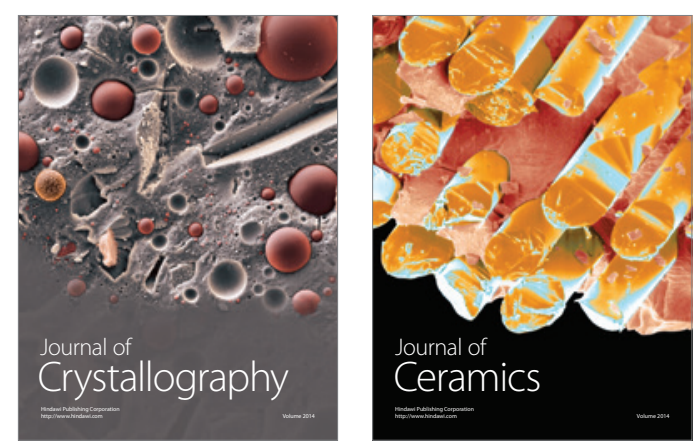
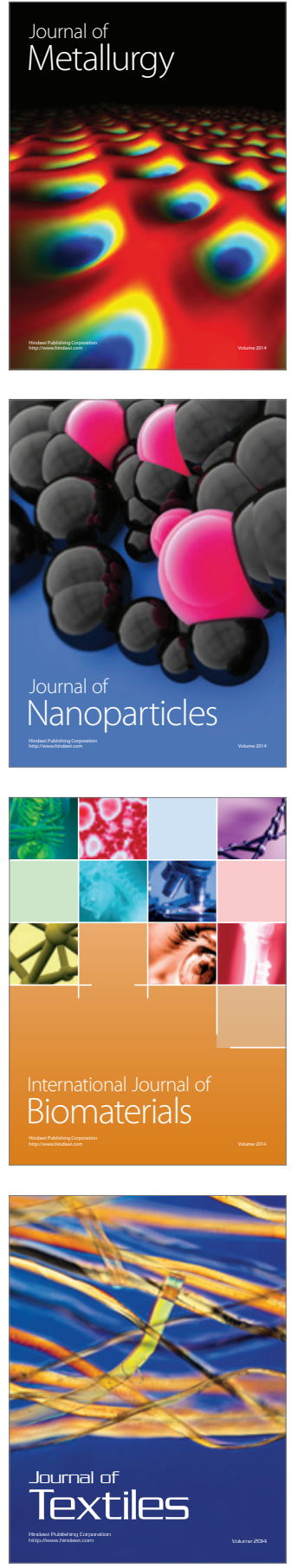